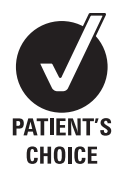

See Editorial commentary, p 710

- Additional table and figure are published online only. To view these files please visit the journal online (http://jnnp.bmj. com)

${ }^{1}$ School of Molecular and Clinical Medicine, University of Edinburgh, Edinburgh, UK ${ }^{2}$ School of Clinical Sciences and Community Health, University of Edinburgh, Edinburgh, UK

${ }^{3}$ Institute of Neurology, Southern General Hospital, Glasgow, UK

${ }^{4}$ Aberdeen Royal Infirmary, Aberdeen, Aberdeen, UK

${ }^{5}$ Ninewells Hospital, University of Dundee, Dundee, UK

${ }^{6}$ Hairmyres Hospital, East Kilbride, UK

7 Sackler Institute of Psychobiological Research, Division of Community Based Sciences, Faculty of Medicine, University of Glasgow, Glasgow, UK

\section{Correspondence to} Dr Alan Carson, Division of Clinical Neurosciences, Western General Hospital, Edinburgh EH4 2XU, UK; a.carson@ed.ac.uk

Received 11 June 2010 Revised 24 November 2010

Accepted 30 November 2010 Published Online First

21 January 2011

\title{
Disability, distress and unemployment in neurology outpatients with symptoms 'unexplained by organic disease'
}

\author{
A Carson, ${ }^{1} \mathrm{~J}$ Stone, ${ }^{1} \mathrm{C}$ Hibberd, ${ }^{1} \mathrm{G}$ Murray, ${ }^{2} \mathrm{R}$ Duncan, ${ }^{3} \mathrm{R}$ Coleman, ${ }^{4} \mathrm{C}$ Warlow, \\ R Roberts, ${ }^{5}$ A Pelosi, ${ }^{6} \mathrm{~J}$ Cavanagh, ${ }^{7} \mathrm{~K}$ Matthews, ${ }^{5} \mathrm{R}$ Goldbeck, ${ }^{4} \mathrm{C}$ Hansen, ${ }^{1}$ \\ M Sharpe ${ }^{1}$
}

\begin{abstract}
Objectives To determine the disability, distress and employment status of new neurology outpatients with physical symptoms unexplained by organic disease and to compare them with patients with symptoms explained by organic disease.
\end{abstract}

Methods As part of a cohort study (the Scottish Neurological Symptoms Study) neurologists rated the extent to which each new patient's symptoms were explained by organic disease. Patients whose symptoms were rated as 'not at all' or only 'somewhat' explained by disease were considered cases, and those whose symptoms were 'largely' or 'completely' explained by disease were considered controls. All patients completed self-ratings of disability, health status (Medical Outcomes Study Short Form 12-Item Scale (SF-12)) and emotional distress (Hospital Anxiety and Depression Scale) and also reported their employment and state financial benefit status.

Results 3781 patients were recruited: 1144 (30\%) cases and 2637 (70\%) controls. Cases had worse physical health status (SF-12 score 42 vs 44; difference in means $1.7(95 \% \mathrm{Cl}-2.5$ to 0.9$))$ and worse mental health status (SF-12 score 43 vs 47; difference in means $-3.5(95 \% \mathrm{Cl}-4.3$ to to 2.7$))$. Unemployment was similar in cases and controls ( $50 \%$ vs $50 \%$ ) but cases were more likely not to be working for health reasons (54\% vs $37 \%$ of the $50 \%$ not working; OR $2.0195 \% \mathrm{Cl}$ 1.6 to 2.4$))$ and also more likely to be receiving disabilityrelated state financial benefits (27\% vs $22 \%$; (OR 1.3 , $95 \% \mathrm{Cl} 1.1$ to 1.6$)$.

Conclusions New neurology patients with symptoms unexplained by organic disease have more disability-, distress- and disability-related state financial benefits than patients with symptoms explained by disease.

\section{INTRODUCTION}

We know that one-third of neurology outpatients have symptoms, such as pain, weakness and sensory disturbance, that are not explained by recognised 'organic' disease. ${ }^{1-4}$ But are these patients really ill? In other words, do they just have symptoms, or are such symptoms actually associated with disability and distress, and is this reflected in their employment status and receipt of disability-related state financial benefits?

A previous study we conducted of symptoms unexplained by organic disease suggested that neurology patients with this problem were at least as disabled and distressed as patients with neurological disease, but it was of only a small sample ( 90 patients with unexplained symptoms) recruited from only one service. ${ }^{1}$ In this study, we aimed to determine the disability, distress and employment status of more than 1000 consecutive cases with symptoms unexplained by disease, who were prospectively identified as part of a large multicentre study of new neurology outpatients, and to compare these with those of controls from the same cohort whose symptoms were explained by neurological disease.

\section{METHODS}

The Scottish Neurological Symptoms Study was a prospective, multicentre, cohort study of NHS neurology outpatients in Scotland. Ethical approval for the study was granted by a Multicentre Research Ethics Committee. This paper reports a case control analysis of study baseline data.

\section{Participating clinics}

Thirty-six out of 38 consultant neurologists, working across all four Scottish NHS neurology centres, participated. Patients were recruited from their general neurology clinics (including their supervised trainee clinics) in the main Scottish neurological centres-Aberdeen, Dundee, Edinburgh and Glasgow, and associated peripheral clinics in Airdrie, East Kilbride, Falkirk, Inverness, Perth, Stirling, Vale of Leven and Wishawbetween December 2002 and February 2004. All the clinics sampled took mainly general practice referrals with patients allocated by medical records staff according to availability of appointment. Tertiary clinics, where patients required a verified diagnosis to attend (such as multiple sclerosis clinics), and emergency clinics were excluded.

\section{Patients}

All newly referred patients at the participating clinics were potentially eligible for inclusion. The exclusion criteria were: age less than 16, cognitive or physical impairment of a degree that precluded informed consent, inability to read English or if the neurologist identified the patient as unsuitable for the study (eg, too distressed, terminally ill). New patients included patients with existing neurological diagnoses who had been re-referred from primary care. Patients were sent information about the study prior to their appointment with the neurologist. After the consultation, they were invited by their neurologist to speak to a research 
assistant. Consent was obtained from patients willing to participate.

Immediately following the initial consultation, neurologists were asked to complete a four-point Likert scale: 'To what extent do you think this patient's clinical symptoms are explained by organic disease?-'not at all,' 'somewhat,' 'largely' or 'completely.'1 Operational criteria were provided to guide ratings (supplementary figure 1 ).

\section{Measures}

Following the initial neurological consultation, all participating patients completed a self-report questionnaire which included the following measures:

- Demographics including age and sex.

- Reported disability (Health status): using the Medical Outcomes Study Short Form 12-item Scale (SF-12), ${ }^{5}$ which examines health status across eight domains and in two composite scores of physical and mental health status. We calculated the 'raw' score in each of the domains as a percentage and also the two composite scores as recommended by the authors.

- Emotional distress using the Hospital Anxiety and Depression scale (HAD). ${ }^{67}$

- Employment Status and receipt of state financial benefits by patient self-report. We asked specifically whether patients were (a) in paid employment (and, if not, whether this was because of health problems); (b) in receipt of income support, unemployment benefits, disability living allowance or incapacity benefit.

\section{Analysis}

First, we calculated the number of patients in each of the four 'organicity' groups. We then amalgamated those patients whose symptoms were rated as 'not at all explained' and 'somewhat' explained by organic disease and classified them as having symptoms 'unexplained' by disease (cases) and patients who were rated as having symptoms 'largely' and 'completely' explained by disease as having 'explained' symptoms (controls). We then compared the cases and controls using the difference in means and ORs.

\section{RESULTS}

Patients were recruited between 16 December 2002 and 26 February 2004. During this period, a total of 4299 new patients attended the designated clinics. Recruitment to the study is summarised in figure 1 . The final sample was of 3781 patients (88\% of all attendees and $91 \%$ of all eligible outpatients), of whom 1144 patients ( $30 \%$ of the total) were rated by neurologists as having symptoms 'not at all' ( $\mathrm{n}=446 ; 12 \%)$ or only 'somewhat explained' ( $\mathrm{n}=698 ; 18 \%$ ) by disease; they were the 'unexplained' cases. The medical diagnoses given to the cases have been described in detail elsewhere. ${ }^{78}$ The remaining 2637 patients had symptoms which were 'largely' ( $\mathrm{n}=940 ; 25 \%)$ or 'completely explained' ( $n=1697 ; 45 \%$ ) by organic disease; they were the 'explained' controls. (We have also analysed the data across all four groups and include this as supplementary table 1).

Cases were, on average, 4 years younger and more likely to be female than controls (table 1). They had lower scores in all SF-12 individual domains, including all the disability domains including physical and social function, and physical and emotional role function. Cases also had a higher level of emotional distress on the SF-12 mental health scale and on the Hospital Anxiety and Depression Scale.

A similarly large proportion of both cases and controls reported not being in paid employment (50\% vs 50\%). However,

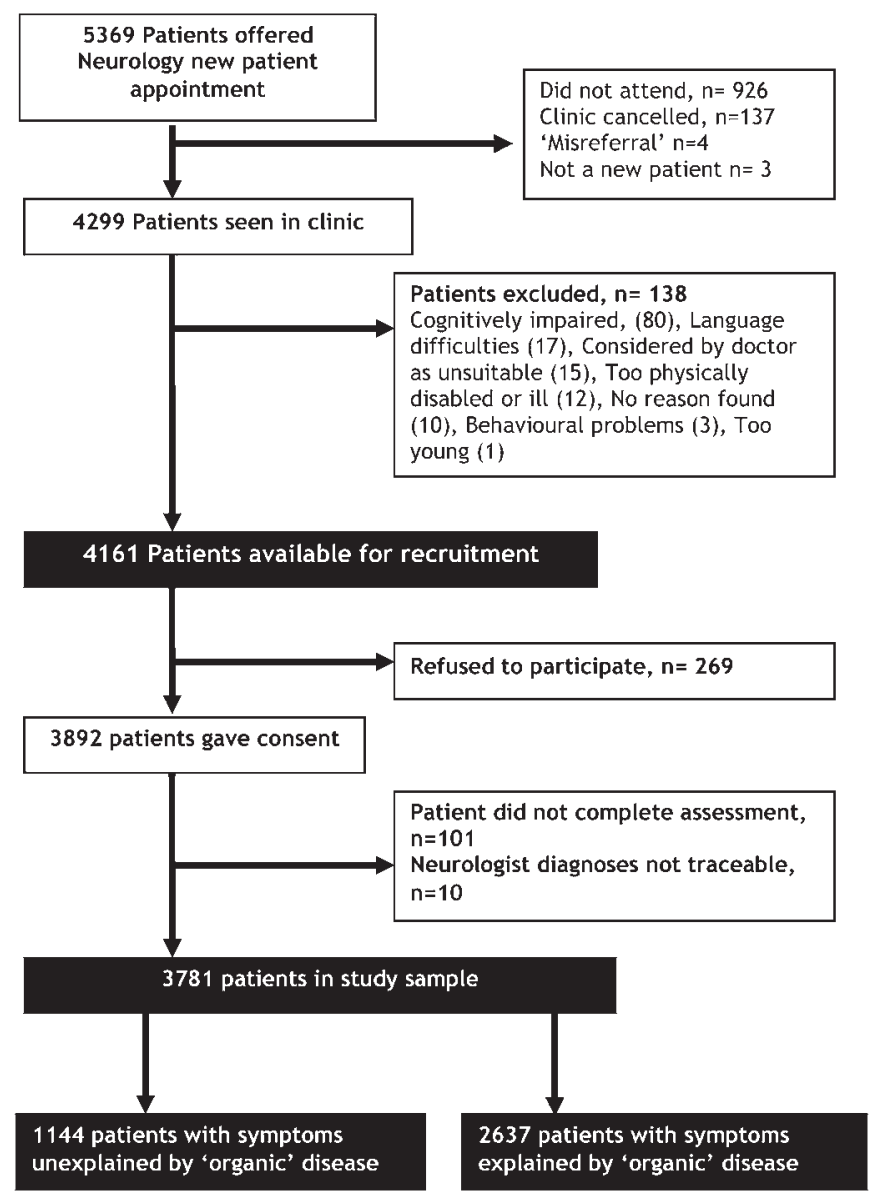

Figure 1 Flow chart of patient recruitment into study.

of those, unemployed cases were more likely to report that they were not working because of ill health (26\% vs 18\%). This difference was reflected in the finding that cases were also more likely to be in receipt of disability-related state financial benefits (27\% vs $22 \%$ : OR $1.3,95 \%$ CI 1.1 to 1.5 ).

\section{DISCUSSION}

We found substantial self-reported disability, distress and unemployment in patients with symptoms 'unexplained' by 'organic' disease. All these variables were more severe in cases than controls. Furthermore, the cases were more likely to report unemployment for reasons of ill health and to be in receipt of disability-related state financial benefits.

These findings clearly indicate that patients with symptoms 'unexplained' by organic disease are not merely the 'worried well.' Rather, they have substantive self-reported disability, distress and associated unemployment. While their degree of disability and distress was actually statistically greater than that of controls with neurological disease, this difference is around the minimum considered clinically significant, ${ }^{9}{ }^{10}$ A more conservative interpretation of these data would therefore be that they are similar to patients with neurological disease on these characteristics.

Although cases had greater rates of health-related unemployment and disability-related state financial benefits than controls, the majority of patients with symptoms unexplained by organic disease were actually in work. This observation does not support anecdotal suggestions that all such patients are motivated by work avoidance and receipt of benefits. 
Table 1 Disability, distress and employment status of cases with symptoms 'unexplained by organic disease' and controls with symptoms 'explained by organic disease'

\begin{tabular}{|c|c|c|c|}
\hline & Cases & Controls & $\begin{array}{l}\text { OR difference in } \\
\text { means }(95 \% \mathrm{Cl})\end{array}$ \\
\hline Age, mean (SD) & $43.6(14.4)$ & $47.5(17.0)$ & $-3.85(-4.98$ to -2.72$)$ \\
\hline Female, \% (n/N) & $65.3(747 / 1144)$ & $53.6(1414 / 2637)$ & $1.63(1.41$ to 1.88$)$ \\
\hline \multicolumn{4}{|c|}{ Medical Outcomes Study Short Form 12-Item Scale, mean (SD)* } \\
\hline General health & $42.6(26.0)$ & $48.7(24.7)$ & $-6.15(-7.90$ to -4.41$)$ \\
\hline Physical functioning & $63.9(38.4)$ & $66.9(36.8)$ & $-2.99(-5.58$ to -0.40$)$ \\
\hline Role physical & $50.0(46.7)$ & $56.1(45.0)$ & $-6.02(-9.18$ to -2.86$)$ \\
\hline Bodily pain & $58.0(35.8)$ & $67.2(34.5)$ & $-9.23(-11.66$ to -6.81$)$ \\
\hline Social functioning & $62.3(34.7)$ & $69.2(33.6)$ & $-6.91(-9.27$ to -4.56$)$ \\
\hline Vitality & $39.5(27.7)$ & $44.4(28.0)$ & $-4.90(-6.85$ to -2.96$)$ \\
\hline Mental health & $54.5(25.5)$ & $61.4(24.0)$ & $-6.94(-8.63$ to -5.24$)$ \\
\hline Role emotional & $64.7(43.1)$ & $75.2(38.9)$ & $-10.48(-13.28$ to -7.69$)$ \\
\hline Composite score-physical health status & $42.2(12.5)$ & $43.9(11.7)$ & $-1.72(-2.55$ to -0.89$)$ \\
\hline Composite score-mental health status & $43.4(12.1)$ & $46.9(11.3)$ & $-3.53(-4.33$ to -2.73$)$ \\
\hline \multicolumn{4}{|l|}{ Hospital Anxiety and Depression Scale, mean (SD)* } \\
\hline Anxiety subscale & $7.9(5.0)$ & $6.4(4.5)$ & 1.51 (1.19 to 1.84$)$ \\
\hline Depression subscale & $5.9(4.9)$ & $4.7(4.2)$ & $1.21(0.91$ to 1.52$)$ \\
\hline Total score & $13.8(8.9)$ & $11.1(7.8)$ & $2.73(2.16$ to 3.30$)$ \\
\hline Not in paid employment, \% (n/N) & $49.5(563 / 1137)$ & $49.9(1313 / 2629)$ & $0.98(0.86$ to 1.13$)$ \\
\hline If not, was this because of health, $\%(n / N) \dagger$ & $54.2(297 / 548)$ & $37.4(470 / 1258)$ & 1.98 (1.62 to 2.43$)$ \\
\hline On income support/unemployment benefit, \% (n/N) & $19.7(224 / 1135)$ & $16.0(417 / 2612)$ & $1.29(1.08$ to 1.55$)$ \\
\hline $\begin{array}{l}\text { In receipt of incapacity benefit or disability living } \\
\text { allowance, } \%(n / N)\end{array}$ & $27.0(307 / 1137)$ & $21.9(573 / 2614)$ & $1.32(1.12$ to 1.55$)$ \\
\hline
\end{tabular}

This study has the strength of being of a large and representative sample of neurology patients. However, it also has limitations: although almost all Scottish neurologists participated in the study, not all their clinics were sampled, and specialised clinics such as neurovascular and memory clinics were not included; consequently, patients with these disorders may be under-represented. Similarly we cannot be certain that Scottish neurological practice is similar to neurological practice round the world, although the prevalence rates of the common neurological disorders in patients attending the clinics sampled would suggest it was.

Although disability-related state financial benefits are subject to independent assessment and, in a small number of cases, antifraud investigations, much of the information used to assess such claims is still based upon self-report and cannot therefore be regarded as completely objective. Furthermore, absolute rates of health-related unemployment and the uptake of financial benefits may be influenced by economic conditions as well as by illness.

Among other limitations was our approach of 'lumping' patients with symptoms unexplained by organic disease into one group. While we believe that there are sound theoretical reasons for doing this, ${ }^{11}$ others may prefer to 'split' this group into many separate conditions. Furthermore, we did not seek to determine the factors causing the observed disability; these are likely to include a variety of factors including, but not exclusively, psychiatric illness. Finally, our 'unexplained' cases were slightly younger and more likely to be female; this may influence the reported rates of disability and distress.

Previous studies of specific diagnostic groups including psychogenic seizures, ${ }^{12-14}$ psychogenic sensory loss ${ }^{15}$ and psychogenic movement disorders ${ }^{16}{ }^{17}$ have also found that these patients have a degree of physical disability similar to that of patients with neurological disease. A retrospective Dutch study of a consultation liaison psychiatry service ${ }^{18}$ included 544 patients who had been diagnosed as having a somatoform disorder, of whom 215 had a conversion disorder, and found a high rate of unemployment among the older patients with somatoform symptoms but not among younger patients. Crimlisk et al, in a study of 64 patients with motor conversion disorder at a tertiary centre, found that $77 \%$ of their cohort had held jobs prior to symptom onset, but only $11 \%$ were still working at 6 years' follow-up. ${ }^{19}$ A recent cohort study of psychogenic seizures in the West of Scotland described very high rates of unemployment (90\%) and uptake of benefits $(62 \%){ }^{20}$ We found a lower rate of unemployment in our cohort. We suspect this was due to two factors: first, we distinguished between those whose unemployment was due to their health complaint and those who were unemployed for other reasons; second, we studied a sample more representative of general neurology clinic attenders.

In summary, our date indicates that neurology patients with symptoms unexplained by disease are not merely the "worried well' but are demonstrably ill by the usually applied criteria of disability and distress. These data make a strong case for the development and implementation of targeted interventions for this group of patients. It is however imperative that such potentially complex interventions are properly tested in welldesigned randomised controlled trials before they are implemented. Researchers should consider including economic measures into trials as successful treatment could not only improve the quality of patients lives but also help them to return to work.

Funding Chief Scientist Office, Scotland, NHS Quality Improvement Scotland. Competing interests None.

Ethics approval Ethics approval was provided by the Muti-centre Research Ethics Committe Scotland.

Provenance and peer review Not commissioned; externally peer reviewed. 


\section{REFERENCES}

1. Carson AJ, Ringbauer B, Stone J, et al. Do medically unexplained symptoms matter? A prospective cohort study of 300 new referrals to neurology outpatient clinics. J Neurol Neurosurg Psychiatry 2000;68:207-10.

2. Reid S, Wessely S, Crayford T, et al. Medically unexplained symptoms in frequent attenders of secondary care: a retrospective study. BMJ 2001;322:767.

3. Fink $\mathbf{P}$, Steen HM, Sondergaard L. Somatoform disorders among first time referrals to a neurology service. Psychosomatics 2005:46:540-8.

4. Lempert T, Dieterich $M$, Huppert D, et al. Psychogenic disorders in neurology: frequency and clinical spectrum. Acta Neurol Scand 1990;82:335-40.

5. Ware J Jr, Kosinski M, Keller SD. A 12-Item Short-Form Health Survey: construction of scales and preliminary tests of reliability and validity. Med Care 1996;34:220-33.

6. Zigmond AS, Snaith RP. The hospital anxiety and depression scale. Acta Psychiatr Scand 1983;67:361-70.

7. Stone $\mathbf{J}$, Carson A, Duncan $\mathrm{R}$, et al. Who is referred to neurology clinics? - The diagnoses made in 3781 new patients. Clin Neurol Neurosurg 2010;112:747-51.

8. Stone J, Carson A, Hibberd C, et al. Symptoms 'unexplained by organic disease' in 1144 new neurology outpatients: how often does the diagnosis turn out to be wrong? Brain 2009;132:2878-88

9. Samsa G, Edelman D, Rothman ML, et al. Determining clinically important differences in health status measures: a general approach with illustration to the Health Utilities Index Mark II. Pharmacoeconomics 1999;15:141-55.

10. Puhan MA, Frey M, Buchi S, et al. The minimal important difference of the hospital anxiety and depression scale in patients with chronic obstructive pulmonary disease. Health Qual Life Outcomes 2008;6:46.
11. Wessley S, Neuman C, Sharpe M. Functional somatic syndromes: one or many? Lancet 1999;354:936-9.

12. Reuber M, Pukrop R, Bauer J, et al. Outcome in psychogenic non-epileptic seizures: a 1 to 10 year follow up of 164 patients. Ann Neurol 2003;53:305-11.

13. LaFrance $\mathbf{W} \mathbf{J r}$, Syc S. Depression and symptoms affect quality of life in psychogenic nonepileptic seizures. Neurology 2009;73:366-71.

14. Lempert T, Schmidt D. Natural history and outcome of psychogenic seizures: a clinical study in 50 patients. J Neurol 1990;237:35-8.

15. Stone J, Sharpe $M$, Rothwell $P$, et al. The 12 year prognosis of unilatera functional weakness and sensory disturbance. J Neurol Neurosurg Psychiatry 2003:74:591-6.

16. Anderson KE, Gruber-Baldini AL, Vaughan CG, et al. Impact of psychogenic movement disorders versus Parkinson's on disability, quality of life, and psychopathology. Mov Disord 2007;22:2204-9.

17. Feinstein A, Stergiopopoulos V, Fine J, et al. Psychiatric outcome in patients with a psychogenic movement disorder: a prospective study. Neuropsychiatry Neuropsychol Behav Neurol 2001;14:169-76.

18. Thomassen R, van Hemert AM, Huyse FJ, et al. Somatoform disorders in consultation-liaison psychiatry: a comparison with other mental disorders. Gen Hosp Psychiatry 2003;25:8-13.

19. Crimlisk HL, Bhatia K, Cope H, et al. Slater revisited: a 6 year follow up study of patients with medically unexplained motor symptoms. BMJ 1998;316:582-6.

20. McKenzie P, Oto M, Russell A, et al. Early outcomes and predictors in 260 patients with psychogenic nonepileptic attacks. Neurology 2010;74:64-9.

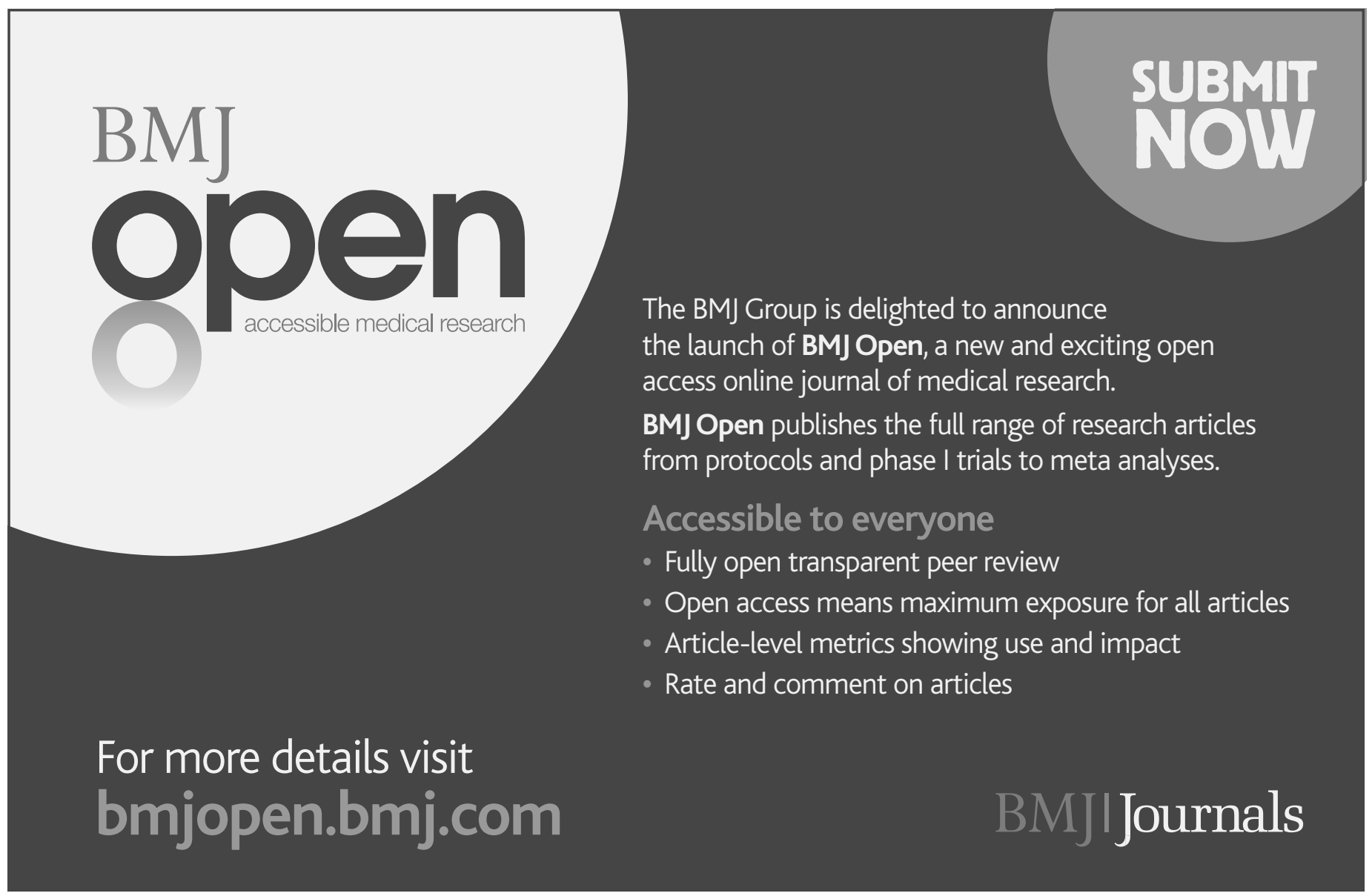

